\title{
PARENT HOSTILITY AND SPIN-OUT PERFORMANCE
}

\author{
DR. SASCHA G. WALTER \\ Lancaster University Management School \\ Lancaster, LA1 4YX, UK \\ Tel: +44 1524594847 \\ Fax: +44 1524594743 \\ Email: s.walter@lancaster.ac.uk \\ DR. SIMON HEINRICHS \\ Hermes Fulfilment GmbH \\ Hamburg, 22179, Germany \\ Tel: +4940460414842 \\ Fax: + 494064644842 \\ Email: simon.heinrichs@hermes-europe.de \\ DR. ACHIM WALTER \\ Christian-Albrechts-University Kiel \\ Kiel, 24118, Germany \\ Tel: +494318803999 \\ Fax: +494318803213 \\ Email: walter@bwl.uni-kiel.de
}

\begin{abstract}
Prior research has focused on the performance implications of positive or neutral parent-child relationships, but neglected negative, conflict-laden relationships. This study explores from an embeddedness perspective whether parent hostility (degree to which an incumbent firm disapproves of the spawning of a spin-out from within its ranks) affects spin-out performance and how spin-outs can effectively react to it. Analyses of 144 technology spin-outs support our arguments that spin-outs suffer negative consequences from hostility. These are less severe, however, if the spin-out pursues effective network development.
\end{abstract}

Keywords: spin-out, parent hostility, performance, entrepreneurship, technology

JEL: L26, M13

Acknowledgements: Helpful comments from Sarah Jack, MB Sarkar and two anonymous reviewers are gratefully acknowledged. We thank Tomi Laamanen for the editorial guidance. An earlier version of the manuscript (Walter, S. G., Heinrichs, S., \& Walter, A. (2013). Spawned with a Rusty Spoon: When and How can Spin-outs Cope with Parent Hostility? Academy of Management Proceedings, 1-6) also considered environmental contingencies (market and technological turbulence) which we omitted here for space reasons. The findings indicate that spin-outs in turbulent markets are better able to cope with hostility.

This article has been accepted for publication and undergone full peer review but has not been through the copyediting, typesetting, pagination and proofreading process, which may lead to differences between this version and the Version of Record. Please cite this article as doi: $10.1002 / \mathrm{smj} .2201$

This article is protected by copyright. All rights reserved. 


\section{INTRODUCTION}

Spin-outs (entrepreneurial ventures by ex-employees) are legion in many high-tech industries and are well-known as strong innovators (Agarwal et al., 2004). A growing body of literature has highlighted that parent relations allow spin-outs to outperform other new entrants (Agarwal et al., 2004; Andersson et al., 2012; Eriksson \& Moritz Kuhn, 2006; Lindholm Dahlstrand, 1997; Wennberg et al., 2011). Indeed, many spin-outs are said to be 'spawned with a silver spoon' (Chatterji, 2009: 185) when close relationships to the parent firm provide them with benefits that other start-ups lack such as access to parent knowledge and networks (Agarwal et al., 2004; Sapienza et al., 2004). However, many of these benefits depend on the parents' benevolence and not all parents appreciate spin-outs. Often they perceive spin-outs as predators, stealing ideas and innovations (Klepper \& Sleeper, 2005). The name 'dirty dozen', given to the founders of the first IBM spin-out, is illustrative (McKendrick et al., 2009).

Parent hostility — the degree to which an incumbent firm disapproves of the spawning of a spin-out from within its ranks — can also manifest in anti-spinout policies, such as lawsuits over intellectual property (Klepper \& Sleeper, 2005). Since relatively little is known about how parent hostility impacts spin-outs, we attempted to explore some fundamental questions for a theory-based understanding of parent-child firm relations: How does parent hostility influence spin-out performance? How can spin-outs respond effectively to hostility?

Our study builds on existing work illuminating the performance impacts of parent-child relations. Prior studies have highlighted the importance of parental support in the development of different types of child firms in general, including divested units (e.g., Moschieri, 2011), spin-offs (e.g., Semadeni \& Cannella, 2011), and spin-outs (e.g., Agarwal et $a l ., 2004) .{ }^{1}$ However, a few gaps remain in areas crucial to our understanding of parent-child relationships. First, although conflict between a spin-out's founders and the parent firm can be

\footnotetext{
${ }^{1}$ The terminology related to start-ups is often confusing. Following Agarwal et al. (2004), we define spin-offs as ventures intentionally created by an incumbent firm, whereas spin-outs are created by ex-employees without intention one the part of the incumbent. These organizational forms differ in start-up rationales and equity involvement of the parent (Hellmann, 2007; Parhankangas \& Arenius, 2003; Semadeni \& Cannella, 2011). This article is protected by copyright. All rights reserved.
} 
an antecedent of spin-out formation (Klepper \& Thompson, 2010; Thompson \& Chen, 2011) and although many scholars assume parents will react negatively to spin-outs (e.g., Klepper \& Sleeper, 2005; Lindholm, 1994; McKendrick et al., 2009), prior research has focused on benevolent or neutral spin-off parents (Parhankangas \& Arenius, 2003, Woo et al., 1992), while neglecting cases of parent hostility towards spin-outs. This is surprising, given that hostility can cause major problems for spin-outs, such as time- and money-consuming litigation (Klepper \& Sleeper, 2005). To be successful, founders must know when consequences of hostility are more severe and how to defend against it. Understanding hostility effects can also guide managers of the parent firm in their decision about whether to respond cooperatively or competitively to a spin-out. Second, while previous studies have adopted resource- or knowledge-based perspectives and focused on the parent-child dyad (e.g., Agarwal et al., 2004), they have not taken into account the wider network effects of this relationship. A parent's influence on a spin-out's performance may flow not only directly via the dyad (e.g., by providing only limited or no support), but also more indirectly via the network (e.g., by hindering the spin-out from establishing third-party ties). Neglecting the latter involves a risk of underestimating the parent's role.

Our study addresses the above gaps by examining whether parent hostility impairs spinout performance, in terms of time to breakeven, and what counter-strategies mitigate the potentially negative effect of parent hostility on spin-out performance. We adopt the perspective of embeddedness theory, with its basic premise that personal relationships develop alongside economic exchanges and that this social structure provides governance and access benefits in interfirm networks (Granovetter, 1985; Uzzi, 1997). Embeddedness theory provides a powerful framework for studying the performance consequences of dyadic relationships within a more complex social structure (Gulati et al., 2000; Uzzi \& Gillespie, 2002). In this context, we make two key points. One, ceteris paribus, parent hostility hinders child performance because it impedes transactions of the spin-out not only with the parent but This article is protected by copyright. All rights reserved. 
also with the parents' partners. Two, hostility effects are less severe under circumstances in which the parent is less willing or less able to act upon its hostility. These are cases in which a spin-out pursues a strategy to counter parent hostility, such as focusing on different products than the parent (product differentiation) or establishing ties to industry actors outside the parent's immediate network (network development). Original survey data from 144 technology spin-outs provides empirical support for most of our arguments. The technology setting is particularly well-suited to the purpose of our study because parent hostility often emerges in technology spin-out processes (Klepper \& Sleeper, 2005) where the parent has no discretion over spin-out strategy (Agarwal et al., 2004). The study contributes to the literature on parent-child firm relations by substantiating the phenomenon of parent hostility and to the embeddedness literature by further exploring conflict-laden relationships.

\section{THEORETICAL DEVELOPMENT}

Embeddedness theory has become a prominent means of illuminating interfirm performance differentials (Gulati et al., 2000). It seeks to explain how social structure provides governance and access benefits in interfirm networks (Uzzi \& Gillespie, 2002). According to the logic of embeddedness, economic exchanges become embedded in webs of social relations over time, thereby promoting feelings of reciprocity and trust among the individual actors involved in these exchanges (Granovetter, 1985; Uzzi, 1997). Since trust can substitute for costly contracts and active monitoring, embedded ties are typically viewed as economically efficient (Uzzi, 1996). As a consequence, embeddedness affects actor's decisions about how and with whom to transact, which has important implications for start-ups that must acquire first customers and accumulate supportive resources from new or existing ties (Hite \& Hesterly, 2001; Starr \& Macmillan, 1990). Uncertainty about a start-up's quality and trustworthiness typically leads resource holders and potential customers not to transact with the start-up or to deploy costly safeguards against opportunistic action (Uzzi \& Gillespie, 2002). Embedded

This article is protected by copyright. All rights reserved. 
ties convey access to reliable and inexpensive information on actors in a network, either via previous direct ties or shared third party ties, to overcome such uncertainty (Stuart, 1998).

In line with embeddedness theory, prior research has highlighted how important preexisting strong ties are for start-ups entering industry networks and their social structures (Gulati, 1995; Hallen \& Eisenhardt, 2012; Hoang \& Antoncic, 2003; Uzzi, 1996). A start-up's connection to its parent firm can be such a tie (Semadeni \& Cannella, 2011). ${ }^{2}$ From an embeddedness perspective, child firms can derive two key benefits from strong parent relations. ${ }^{3}$ First, the mechanisms of tie repetition (actors tend to form ties with the same actors repeatedly; Gulati, 1995; Podolny, 1994), and homophily (actors will associate or bond with others similar to them; Stuart \& Sorenson, 2007) increase the likelihood and efficiency of parent-child transactions. Second, the mechanisms of tie transitivity and signaling increase the likelihood and efficiency of transactions with third parties. The tie transitivity argument predicts that actors tend to form ties with their partners' partners because the direct partner can provide reliable information about the new or secondary partner (Gulati, 1995; Hallen \& Eisenhardt, 2012; Podolny, 1994). The signaling argument purports that a child firm's affiliations with its parent firm signal the legitimacy (Moschieri, 2011) and quality (Hallen, 2008) of the former, especially in absence of another way to evaluate the reliability of a newcomer. These four mechanisms build the ground for our theorizing on impacts of parent hostility in the following section.

\section{Parent hostility and its performance consequences}

The literature has proposed that once a spin-out has been announced or registered, parent firms tend to respond in one of many ways, ranging from more friendly to more hostile. Some

2 It may also lie in the parent's interest to sustain a relationship with its progeny because in order to manage or altogether avoid risks associated with child firms, such as lost access to critical resources or increased competition (Moschieri, 2011; Semadeni \& Cannella, 2011).

3 Some studies also point to substantial risks of overembedding with the parent (Clarysse et al., 2011; Sapienza et al., 2004; Semadeni \& Cannella, 2011).

This article is protected by copyright. All rights reserved. 
parents react in a more friendly manner by encouraging and actively supporting spin-outs (Lindholm Dahlstrand, 1997). Other firms adopt a more neutral position, tolerating spin-outs that initially do not compromise the viability of their markets (Klepper \& Sleeper, 2005). But many firms tend to be wary of a spin-out or may even move against it (Garvin, 1983). ${ }^{4}$ In fact, the spin-out process can be prone to conflict, especially when tension between the former employee and employer is part of what has led to spin-out formation in the first place (Hellmann, 2007). Many spin-outs not only disrupt ongoing innovation processes and general social organization, but they also result in the parent losing critical firm-specific skills, routines, and other resources (Phillips, 2002; McKendrick et al., 2009). Concerns about resource misappropriation can lead parents to view spin-outs as 'predators that steal their ideas and innovations' (Klepper \& Sleeper, 2005: 1305). Some firms-Intel is a very popular example (Jackson, 1998: 211-338) —respond to this perceived threat by systematically attempting to prevent or handicap spin-outs through non-compete covenants, intellectual property litigation, or rewards for revealing inventions (Campbell et al., 2012; Thompson \& Chen, 2011). However, to date, the phenomenon of hostility has been relatively neglected in the extant literature.

Some scholars have defined hostility in terms of actual behavior, for instance as 'overt actions by one party toward another that the target perceives as malevolent, unfavorable, or even warlike toward himself or herself' (Doucet, 2004: 761). We offer a definition of parent hostility in terms not of behavior but of attitude, as the degree to which an incumbent firm disapproves of the spawning of a spin-out from within its ranks. Our concept is akin to a cognitive one in psychology, where hostility means 'negative beliefs about and attitudes toward others' (Miller et al., 1996: 323). Conceptualizing hostility as an attitude rather than as a behavior has two distinct advantages. First, hostile behavior may take many forms,

\footnotetext{
${ }^{4}$ Often, the spin-out situation involves the actors in ethical dilemmas. In many cases, it is obvious that incumbents are or become hostile because they believe there has been a breach of ethics on the part of an employee. However, such ethical issues are outside the boundaries of our study. This article is protected by copyright. All rights reserved.
} 
including denial of direct support, law-suits, or moves to discredit the spin-out, (Klepper \& Sleeper, 2005; McKendrick et al., 2009) that to date have not been well researched. Such behavior, however, presupposes a hostile attitude (Ajzen, 1991), and an attitude can be conceptualized more parsimoniously. Second, the attitude concept considers the possibility that parents might sanction unwanted progeny either with an unpredictable delay or not at all, while intentionally or unintentionally motivating their partners to also take hostile action.

We now argue that parent hostility is negatively related to spin-out performance. We captured performance in terms of time to breakeven, defined as the number of full months between a firm's founding and the first time its costs equaled its revenues. This measure is consistent with our theoretical framework which revolves around the notion that spin-outs can mitigate the negative consequences of hostility by deploying certain strategies that aid them in connecting with resource providers and customers despite that hostility. Linking to resource providers lowers the costs of resource acquisition (Starr \& Macmillan, 1990) and linking to customers increases revenues. Both aspects are important, and both are incorporated in the breakeven measure. Moreover, the breakeven measure captures a firm's progress toward profitability and thus toward survival, a critical goal not only for new firms.

Embeddedness research proposes that spin-outs can benefit from privileged access to resource through prior dealings (tie repetition) or through similarity (homophily) with the parent firm (Gulati, 1995; Hallen \& Eisenhardt, 2012; Stuart \& Sorenson, 2007). Tie repetition and homophily lead to initial extensions of trust that can, if accepted and reciprocated, evolve into a self-reinforcing process of trust-building (Uzzi, 1996). Trust in turn makes parent-child transactions more likely to occur and more efficient when they do, which gives a spin-out distinct performance advantages (Agarwal et al., 2004; Eriksson \& Moritz Kuhn, 2006; Wennberg et al., 2011; Phillips, 2002). However, as Uzzi and Gillespie (2002) note, embedded relationships do not automatically develop, and expectations or perceptions of opportunistic action by a spin-out are likely to prompt distrust. This can This article is protected by copyright. All rights reserved. 
interfere with tie repetition and homophily mechanisms and, in turn, lead hostile parents to deny privileges to or otherwise handicap the spin-out (Lindholm, 1994:165), for instance by asserting its intellectual property rights (Klepper \& Sleeper, 2005). Transactions with hostile parents may therefore be more costly or impossible, impeding the spin-out's timely and costefficient resource acquisition.

Hostility is also likely to hamper third-party transactions. Embeddedness theory suggests that, if there is conflict between two parties, a third party cannot collaborate with both without experiencing a 'psychological strain' (Heider, 1958; Granovetter, 1973). To resolve the tension, the third party will either discard one relationship or adjust its perception of the relationship between the parties to restore cognitive balance (Krackhardt, 1987). When choosing among potential partners who may be able to provide similar resources, organizations tend to select the partner with whom there is less uncertainty about whether this tie will produce the desired benefits (Podolny, 1994). Since spin-outs face, like all start-ups, the liabilities of newness and smallness, and are, thus, uncertain partners, a third party is likelier to prefer the parent firm. Consequently, in the presence of parent hostility, the tie transitivity mechanism is unlikely to unfold. Moreover, a hostile parent is likely to disseminate negative information about a spin-out which can overshadow any otherwise helpful signaling mechanisms. A spin-out can thus be cut off from the critical spillovers of reputation that, barring hostility, would lend it legitimacy and social status, and gain it access to financial and social capital within the industry (Higgins \& Gulati, 2003; Shane \& Cable, 2002; Stuart et al., 1999). With such resource disadvantages in the face of hostility, spin-outs of hostile parents should, ceteris paribus, perform worse than other spin-outs. Thus,

Hypothesis 1. The higher the parent hostility, the longer the spin-out's time to breakeven. 


\section{Counter-strategies}

The first counter-strategy we consider is product differentiation, the degree to which the spinout focuses on other products than the parent. Generally, staying in the parent's business is an attractive option, since the spin-out can leverage transferred knowledge and prior business contacts while drawing on a proven business concept. Many spin-outs not only locate in close proximity to the parent firm, but also inherit its product focus (Cooper, 1985). Klepper and Sleeper (2005), finding that $83 \%$ of the spin-outs in their sample initially produced the same lasers that their parents had produced, highlight the importance of non-overlapping product portfolios for positive parent-child relationships. We suggest two reasons why reducing overlaps between its and its parent's product portfolio helps spin-outs mitigate the consequences of hostility.

First, product differentiation reduces parent-child competition, so it lowers the parent's interest in acting on a hostile inclination. A spin-out serving the market with different products is less likely to compromise the parent's revenue streams. Even a hostile parent will be less likely to regard the progeny as a threat in such a case, and thus less likely to invest valuable resources and time in fighting it. The spin-out in this scenario may grow unharmed. This is consistent with Klepper and Sleeper's (2005) finding that so many of the spin-outs in their sample eventually differentiated their product strategy from that of their parents.

Moreover, spin-outs can serve parents as customers or subcontractors (Lindholm Dahlstrand, 1997), a relationship that might provide the spin-out with access to critical resources or promote early sales growth. A hostile parent is more likely to consider this option, when the benefits of those economic exchanges outweigh the cost and may take the firms' relative competitive position into account. A spin-out that differentiates its product portfolio, thus, increases its chances of engaging in beneficial exchanges with the parent.

Second, product differentiation constrains a parent's ability to handicap unwelcome offspring. Undifferentiated spin-outs directly compete with more experienced, better 
established, and often larger parent organizations that generally possess the resources required to take retaliatory action (Thompson \& Chen, 2011) such as initiating price wars or wooing away key customers. Sapienza et al. (2004), who illustrate the disadvantageous market position of entrants, demonstrate that high overlaps in production and technological knowledge between spin-outs and parent firms not only impede differentiation in the market, but also handicap a spin-outs' sales growth. Retaliation measures, however, are costlier or even impossible in market segments a parent does not currently serve. To put it differently, even if a parent firm's management was punitively hostile to a spin-out, the costs involved in moving against it in a different market segment might be prohibitively high. Thus,

Hypothesis 2. Product differentiation weakens the positive relationship between parent hostility and the spin-out's time to breakeven.

The literature has shown strategies for creating interfirm networks to be important for start-up performance (e.g., Hite \& Hesterly, 2001; Stuart \& Sorenson, 2007). This leads us to consider network development, the degree to which a spin-out establishes new ties outside the parent's immediate network, as a second counter-strategy. At their founding, many spin-outs benefit from network ties that the founders carry over from their time at the parent firm (Agarwal et al., 2004; Higgins \& Gulati, 2003; Yli-Renko et al., 2001). Since parent and child firms often reside in the same geographic location (Woo et al., 1992), their networks tend to overlap initially (Agarwal et al., 2004; Higgins \& Gulati, 2003). Although the literature regards it as a critical success factor, many new ventures do not focus on developing their networks (Hoang \& Antoncic, 2003; Hite \& Hesterly, 2001; Yli-Renko et al., 2001). However, we suggest that network development can dissipate the harmful consequences of hostility for several reasons.

First, a spin-out pursuing network development links up with new partners, including suppliers, customers, and competitors, that are not directly connected to the parent and are This article is protected by copyright. All rights reserved. 
thus less likely to be subject to its influences. In doing so, the spin-out reduces its parent's ability to sanction or obstruct it, effectively emancipating itself from its influence. New partners - potential resource providers — now need not weigh the social costs of choosing between the child and the parent, so the spin-out will face lower barriers to mobilizing critical resources. Second, where a potential partner's previous contact with the parent is limited, it is less likely to seek information on the spin-out from the parent or to weigh such information as highly as that coming from other market actors. Some spin-outs tend to cover their tracks, e.g. by keeping their origin secret, in order to avoid communication between potential partners and their parent firms (Klepper \& Sleeper, 2005). Third, in the face of hostile behavior by the parent, child firms can gain self-determination, flexibility, and discretion over their resource options by developing exclusive contacts and accessing information from new network ties (Moran, 2005). More and faster access to a broader spectrum of knowledge about valuable opportunities enhances firm performance (e.g., Zaheer \& Bell, 2005). Finally, prior research into network inertia suggests that established (as opposed to new) organizations resist or have difficulties dissolving existing network ties and forming new ones (Kim et al., 2006). If a spin-out has developed its network independently, network inertia means that its parent is less likely to approach its new partners, which makes these a 'safe haven' for a spin-out entering an industry network. Thus,

\section{Hypothesis 3. Network development weakens the positive relationship between parent hostility and the spin-out's time to breakeven.}

\section{METHODS}

\section{Sample, procedure, and response validity}

We assembled a preliminary list of spin-outs from keyword searches of the internet and from lists of exhibitors at industry fairs. The search terms were broadly defined to include any new This article is protected by copyright. All rights reserved. 
firm originating from an incumbent firm. Firms were sampled on three criteria: (1) At least one founder worked for the parent immediately before founding the spin-out; (2) the spinout's business model is built on a technology transferred to it from the parent; and (3) the spin-out is headquartered in Germany. This resulted in a list of 1,168 likely technology spinouts. Of these, we selected 648 firms at random and called them to reconfirm that they met our sampling criteria, to schedule interviews, and to ask for referrals to other spin-out founders. Trained interviewers then conducted face-to-face interviews with spin-out founders who were willing to participate. This resulted in 144 cases with complete performance data.

The spin-outs were on average 7.77 years old $(\mathrm{sd}=3.11)$, had 24.25 full-time employees $(\mathrm{sd}=85.67)$, and were active in the fields of software $(34 \%)$, electronics $(27 \%)$, nanotechnology and new materials (10\%), biotechnology $(8 \%)$, and others $(21 \%)$. We sampled from multiple industries to increase the generalizability of our findings and to complement prior studies that had a mono-industry focus (e.g., Agarwal et al., 2004; Chatterji, 2009). Data on 105 parent firms was available. These firms averaged 43.47 years old $(\mathrm{sd}=48.03)$ and 38,233 employees $(\mathrm{sd}=92,501.57)$. The average geographical distance between parent and child firm was $138.49 \mathrm{~km}($ median $=25.10, \mathrm{sd}=203.13)$. A comparison of responding and non-responding firms in terms of age and size (number of employees) indicated a low risk of non-response bias. Harman's one-factor test, using a hostility measure constructed by independent coders, and a validation of breakeven data based on financial statements $(n=42, r=0.88, p<0.001)$ strengthened our belief that a common method bias was no serious threat.

\section{Measures}

Our dependent variable, time to breakeven, was measured as the number of full months between the firm's founding (its date of incorporation) and the moment at which its costs equaled its revenues so that it started to make profits (as reported by the respondent).

This article is protected by copyright. All rights reserved. 
Confirming criterion validity, time to breakeven significantly correlated with our survey measures for goal achievement in terms of return on investment $(r=-0.41, p<0.001)$, profits $(r=-0.35, p<0.001)$, market share $(r=-0.33, p<0.001)$, and sales $(r=-0.37, p<0.001)$.

For our independent variables, we measured parent hostility similar to Doucet (2004). Three coders reviewed case studies for each spin-out independently of one another and rated a parent firm either as 1 (for 'hostile') if the reports evidenced some form of disapproval, as reflected by words such as 'litigation', 'lawsuit', or 'turmoil', or as 0 (for 'friendly or neutral') otherwise. We provided the reviewers with our definition of parent hostility but, given the complexity of the phenomenon, not with an exhaustive list of keywords. The case studies were written by our interviewers and complemented the survey by adding information on the parent-child relationship as was available on the internet or from the respondent. The average agreement rate was 94\%, with a Fleiss' Kappa of 0.86 indicating high inter-rater reliability. Remaining discrepancies were resolved through discussion and reaching consensus. In addition, hostility was measured with three reverse-coded reflective items $(\alpha=$ 0.96): 'The management of the parent firm has appreciated the spin-out', 'In the phase of spinning-out, there has always been a benevolent posture', and 'The parent firm was openminded about the idea of creating a spin-out'. The items were, as always unless otherwise stated, measured on a 7-point Likert-scale $(1=$ 'does not apply at all', $7=$ 'applies fully and completely'). Because this hostility measure was non-normally distributed, we dichotomized it using a median split (median $=3.5)$. Overall, both measures correlated highly $(r=0.92, p<$ 0.001). To minimize the likelihood of common method bias, we drew on the coding-based measure in our main analyses and used the survey-based measure for robustness checks.

To measure product differentiation, respondents rated the extent to which the parent and child firm offered similar products (7-point Likert-scale; 1 = 'very similar', 7 = 'very dissimilar') three years after founding. High values indicate that the spin-out pursued a product strategy different from the parent's, whereas low values indicate that the two firms' 
strategies were similar three years after founding. We opted for a lagged measure on the base of Klepper and Sleeper's (2005) finding that spin-outs closely resemble their parents in product focus initially, but later start to differentiate in some cases.

Our measure of network development is conceptually rooted in research suggesting that spin-outs often reside in close geographic proximity to their parents (Woo et al., 1992) and share the same set of network contacts prior to founding (Agarwal et al., 2004; Yli-Renko et al., 2001). Many new contacts established by the spin-out post-founding are, thus, not likely to be directly linked to the parent. Consequently, we asked respondents for the number of partners they had in the year of founding. Partners included key industry actors, namely suppliers, customers, and competitors (Sapienza et al., 2004). Respondents then specified how many of these contacts were newly established after their firm's founding and how many of them resulted from referrals by the parent firm. We calculated the ratios of new, postfounding contacts to total contacts respectively for suppliers, customers, and competitors. Parent referrals were disregarded since they could allow the parent to influence the spin-out indirectly. The three ratios were then summed up to create our composite measure of network development. High values reflect that a spin-out 'renewed' its network by acquiring new partners in the industry, which would be likely to reduce the overlaps in between a parent's and a child's respective networks. Low values show that the spin-out tended to rely on preexisting contacts or referrals from the parent firm, which would lead to significant overlap between the two firms' networks.

We considered several control variables. Product quality was measured with three items $(\alpha=0.75)$ adapted from Atuahene-Gima \& Ko (2001). Start-up experience was measured as the number of start-ups previously created by the spin-out's founders. Initial product similarity captures the degree to which spin-out products resembled parent products in the founding year (7-point Likert-scale; 1 = 'very dissimilar', 7 = 'very similar'). $R \& D$ intensity was measured as the average R\&D expenditure per employee in the first three years.

This article is protected by copyright. All rights reserved. 
Exploration describes as a firm's tendency to experiment with new alternatives rather than refine existing competencies and technologies. It was measured with four items $(\alpha=0.76)$ adapted from Jansen et al. (2006). Confirmatory factor analysis indicates an adequate fit of our measurement models $\left(\chi^{2} / \mathrm{df}=1.24 ; \mathrm{AGFI}=0.84 ; \mathrm{CFI}=0.97 ; \mathrm{IFI}=0.97 ; \mathrm{RMSEA}=\right.$ 0.04 ), with a minimum average variance extracted of 0.46 .

\section{RESULTS}

Table 1 provides the descriptive statistics and correlation matrix. Table 2 reports the results of our negative binomial regression. ${ }^{5,6}$ Supporting Hypothesis 1, parent hostility and a spin-out's time to breakeven were significantly and negatively related in all estimated models. About half of the surveyed ventures encountered some form of parent hostility in their first year $($ mean $=0.50$, Table 1$)$. Overall, hostility seems to protract the spin-outs' time to profitability.

Hypothesis 2 received no support, since the interaction term of hostility and product differentiation was, on average, not statistically significant (average $p>0.10$; cf. Footnote 7 above). Hypothesis 3 was supported: Network development negatively moderated the relationship between hostility and time to breakeven (average $p<0.05$ ); the interaction plot (available from the first author) was also in line with this finding. As a result, spin-outs that formed ties to new industry partners in the founding year can be said to have suffered less from hostility than other spin-outs.

\footnotetext{
${ }^{5}$ Poisson regression and its generalized form, the negative binomial regression, are two ways of dealing with count data (Hausman et al., 1984). The first model assumes that the conditional mean of the outcome is equal to the conditional variance. According to a likelihood-ratio test for overdispersion, the conditional variance of our dependent variable was significantly greater than the conditional mean which runs contrary to the poisson regression's assumption. We therefore used negative binomial regression assuming a gamma distribution for the conditional mean, so conditional mean and variance could vary.

${ }^{6}$ We employed hierarchical moderated regression analysis to test our models (Aiken \& West, 1991). Moreover, Hoetker (2007) and Norton et al. (2004) emphasize that non-linear regression differs from ordinary least square (OLS) regression in its analyses of interactions. We therefore followed Hoetker's (2007) suggestion of graphing the interactions using a procedure developed by Norton et al. (2004). The procedure also calculates average significance levels, from which we inferred the overall significance of our hypothesized interactions. Computations of the condition index (CI) and variance inflation factor (VIF) revealed no serious multicollinẹarity problems $(\mathrm{CI}<3,92$, VIF $<3.40)$.

This article is protected by copyright. All rights reserved.
} 
Conceivably, not only can parent hostility affect venture performance, but (anticipated) venture performance might drive parent hostility when spin-outs with high economic potential cause great financial loss to the parent firm and intensify competition in the market. This would make it a case of simultaneous causality, in which conventional estimation methods yield biased, inconsistent coefficients. Tests recommended by the extant literature (Wooldridge, 2003:121-122), however, indicated that parent hostility did not create an endogeneity problem. As a robustness check, we also considered additional control variables to capture resource flows between parent and spin-out (patent acquisition, parent support, parent-spin-out cooperation, sales to parent, and procurement via parent), spin-out characteristics (product development advantage, exploitation, and technological fields) and industry characteristics (industry competition and market growth). These variables proved statistically insignificant and their inclusion did not change the pattern of our original findings. We also reran our models using the survey-based measure for hostility. The results were virtually identical with our findings from the coding-based measure.

\section{DISCUSSION AND IMPLICATIONS}

Research suggests that the origins of new firms may explain the heterogeneity of their initial resource endowments and, thus, performance. Specifically, spin-outs are said to owe superior access to critical resources and knowledge via the parent firm — a privilege that allows them to outperform de novo start-ups (e.g., Agarwal et al., 2004; Chatterji, 2009; Klepper \& Sleeper, 2005; Wennberg et al., 2011). However, prior research seems to have neglected one important issue: Whether a parent firm grants or denies these benefits may crucially depend on its attitude toward the spin-out. Friendly parents are likely to support and cooperate with a spinout, whereas hostile parents might even combat and obstruct it. Our finding that parent hostility is a frequent problem and that spin-outs from hostile parents take longer to reach breakeven contributes to the literature on parent-child firm relationships. In linking hostility

This article is protected by copyright. All rights reserved. 
to spin-out development, our study may be among the first to theoretically and empirically substantiate the neglected phenomenon of parent hostility. While prior research has indicated that 'inherited' resource advantages enable spin-outs to outperform de novo start-ups (e.g., Agarwal et al., 2004; Chatterji, 2009), our theory suggests that these advantages are a function of parent hostility. In other words, while some spin-outs may 'spawn with a silver spoon' (Chatterji, 2009), benefitting from rightful knowledge transfers and parental support, other spin-outs may 'spawn with a rusty spoon', having to cope with parental sanctions.

While the wider embeddedness literature has highlighted the value of embedded ties (Hallen, 2008; Shane \& Cable, 2002) and explored the risks of being under- or overembedded (Gulati et al., 2000; Uzzi, 1996; Uzzi, 1997), Granovetter (1973) has theorized that conflict-laden relations with one actor impede a party's transactions not only with the immediately problematic actor but also with other actors in the network. Our study adds to this relatively neglected stream in the literature by demonstrating, theoretically and empirically, the negative performance consequences of such a handicapped starting position. Our findings suggest that, in the face of hostility, embedded ties are less valuable to a child firm if it has them in common with its parent. Relying on 'inherited' ties—often an obvious and tempting option for child firms - is then a suboptimal choice. The spin-outs in our study instead were able to alleviate the negative impact of hostility on their performance, when they quickly created ties to new partners including suppliers, customers, and competitors. Although network development incurs risk and costs, child firms faced with hostile parents derive greater benefit from it than from trying to leverage their network legacy.

Our findings also bear on the debate over how parent firms might effectively respond to the spawning of own spin-outs. Some scholars have observed parents rigorously fighting them in hopes of avoiding another competitor (e.g., Jackson, 1998; Klepper \& Sleeper, 2005). Other scholars have highlighted the advantages to the parent of sustaining a cooperative relationship to maintain access to the progeny's resources and technology (e.g., Moschieri, 
2011). Our findings add to this debate that the negative consequences of parent hostility are dissipated by the spin-out's strategy that can limit the parent's ability to sanction it. An understanding of these contingencies may guide managers of the parent firm in their decision about whether to respond cooperatively or competitively to a spin-out.

Our study is not without limitations that are also exciting avenues for future research. First, we sampled from the population of technology spin-outs headquartered in Germany with parents from the same country. Our results are therefore conditional upon and mostly generalizable to this context. Second, our conceptual model builds on embeddedness theory to illuminate the theoretical mechanisms behind the proposed relationships. Given the purpose of our research, we did not draw on advanced methods of structural network analysis but instead used aggregated measures. Third, we limited our model to two theoretically important contingencies of the hostility-performance relationship. Future research could go further by exploring other factors such as a parent's status in terms of power and reputation. Fourth, some established firms disapprove of spin-outs in general and have established anti-spin-out policies to minimize their occurrence. Such 'institutionalized parent hostility' can affect not only performance but also spin-out formation rates, another, exciting area for future research. Finally, our study takes no account of proactive efforts by a spin-out's founders to pave its way by fostering the goodwill of the parent in advance. Such pre-founding championing behavior might secure parental support or, at least, reduce parent hostility by setting-up winwin situations and allaying fears through mutual understanding.

This article is protected by copyright. All rights reserved. 


\section{REFERENCES}

Agarwal R, Echambadi R, Franco AM, Sarkar MB. 2004. Knowledge transfer through inheritance: Spin-out generation, development, and survival. Academy of Management Journal 47(4): 501-522.

Aiken LS, West SG. 1991. Multiple Regressions: Testing and Interpreting Interactions. Sage: Newbury Park et al.

Ajzen I. 1991. The theory of planned behavior. Organizational Behavior and Human Decision Processes 50(2): $179-211$.

Andersson M, Baltzopoulos A, Lööf H. 2012. R\&D strategies and entrepreneurial spawning. Research Policy 41(1): 54-68.

Atuahene-Gima K, Ko A. 2001. An empirical investigation of the effect of market orientation and entrepreneurship orientation alignment on product innovation. Organization Science 12(1): 54-74.

Campbell BA, Ganco M, Franco AM, Agarwal R. 2012. Who leaves, where to, and why worry? Employee mobility, entrepreneurship and effects on source firm performance. Strategic Management Journal 33(1): 65-87.

Chatterji AK. 2009. Spawned with a silver spoon? Entrepreneurial performance and innovation in the medical device industry. Strategic Management Journal 30(2): 185-206.

Clarysse B, Wright M, Van de Velde E. 2011. Entrepreneurial origin, technological knowledge, and the growth of spin-off companies. Journal of Management Studies 48(6): 1420-1442.

Cooper AC. 1985. The role of incubator organizations in the founding of growth-oriented firms. Journal of Business Venturing 1(1): 75-86.

Doucet L. 2004. Service provider hostility and service quality. Academy of Management Journal 47(5): 761-771.

Eriksson T, Moritz Kuhn J. 2006. Firm spin-offs in Denmark 1981-2000 — patterns of entry and exit. International Journal of Industrial Organization 24(5): 1021-1040.

Garvin DA. 1983. Spin-offs and the new firm formation process. California Management Review 25(2): 3-20.

Granovetter M. 1985. Economic action and social structure: The problem of embeddedness. American Journal of Sociology 91(3): 481-510.

Granovetter MS. 1973. The strength of weak ties. American Journal of Sociology 78(6): 1360-1380.

Gulati R. 1995. Social structure and alliance formation patterns: A longitudinal analysis. Administrative Science Quarterly 40(4): 619-652.

Gulati R, Nohria N, Zaheer A. 2000. Strategic networks. Strategic Management Journal 21: 203-215.

Hallen BL. 2008. The causes and consequences of the initial network positions of new organizations: From whom do entrepreneurs receive investments? Administrative Science Quarterly 53(4): 685-718.

Hallen BL, Eisenhardt KM. 2012. Catalyzing strategies and efficient tie formation: How entrepreneurial firms obtain investment ties. Academy of Management Journal 55(1): 35-70.

Hausman J, Hall BH, Griliches Z. 1984. Econometric models for count data with an application to the patentsR\&D relationship. Econometrica 52(4): 909-938.

Heider F. 1958. The Psychology of Interpersonal Relations. Wiley: New York.

Hellmann T. 2007. When do employees become entrepreneurs? Management Science 53(6): 919-933.

Higgins MC, Gulati R. 2003. Getting off to a good start: The effects of upper echelon affiliations on underwriter prestige. Organization Science 14(3): 244-263.

Hite JM, Hesterly WS. 2001. The evolution of firm networks: From emergence to early growth of the firm. Strategic Management Journal 22: 275-286.

Hoang H, Antoncic B. 2003. Network-based research in entrepreneurship: A critical review. Journal of Business Venturing 18(2): 165-187.

Hoetker G. 2007. The use of logit and probit models in strategic management research: Critical issues. Strategic Management Journal 28(4): 331-343.

Jackson T. 1998. Inside Intel. Penguin Putnam: New York.

Jansen JJP, Van Den Bosch FAJ, Volberda HW. 2006. Exploratory innovation, exploitative innovation, and performance: Effects of organizational antecedents and environmental moderators. Management Science 52(11): 1661-1674.

Kim T-Y, Hongseok O, Swaminathan A. 2006. Framing interorganizational network change: A network inertia perspective. Academy of Management Review 31(3): 704-720.

Klepper S, Sleeper S. 2005. Entry by spinoffs. Management Science 51(8): 1291-1306.

Klepper S, Thompson P. 2010. Disagreements and intra-industry spinoffs. International Journal of Industrial Organization 28(5): 526-538.

Krackhardt D. 1987. Cognitive social structures. Social Networks 9(2): 109-134.

Lindholm A. 1994. The Economics of Technology-Related Ownership Changes. Chalmers University of Technology. Göteborg, Sweden.

Lindholm Dahlstrand A. 1997. Growth and inventiveness in technology-based spin-off firms. Research Policy 26(3): 331-344.

This article is protected by copyright. All rights reserved. 
McKendrick DG, Wade JB, Jaffee J. 2009. A good riddance? Spin-offs and the technological performance of parent firms. Organization Science 20(6): 979-992.

Miller TQ, Smith TW, Turner CW, Guijarro ML, Hallet AJ. 1996. Meta-analytic review of research on hostility and physical health. Psychological Bulletin 119(2): 322-348.

Moran P. 2005. Structural vs. relational embeddedness: Social capital and managerial performance. Strategic Management Journal 26(12): 1129-1151.

Moschieri C. 2011. The implementation and structuring of divestitures: The unit's perspective. Strategic Management Journal 32(4): 368-401.

Norton EC, Wang H, Ai C. 2004. Computing interaction effects and standard errors in logit and probit models. The Stata Journal 4(2): 154-167.

Parhankangas A, Arenius P. 2003. From a corporate venture to an independent company: A base for a taxonomy for corporate spin-off firms. Research Policy 32(3): 463-481.

Phillips DJ. 2002. A genealogical approach to organizational life chances: The parent-progeny transfer among silicon valley law firms, 1946-1996. Administrative Science Quarterly 47(3): 474-506.

Podolny J. 1994. Market uncertainty and the social character of economic exchange. Administrative Science Quarterly 39: 458-483.

Sapienza HJ, Parhankangas A, Autio E. 2004. Knowledge relatedness and post-spin-off growth. Journal of Business Venturing 19(6): 809-829.

Semadeni M, Cannella AA. 2011. Examining the performance effects of post spin-off links to parent firms: Should the apron strings be cut? Strategic Management Journal 32(10): 1083-1098.

Shane S, Cable D. 2002. Network ties, reputation, and the financing of new ventures. Management Science 48(3): 364-381.

Starr JA, Macmillan IC. 1990. Resource cooptation via social contracting: Resource acquisition strategies for new ventures. Strategic Management Journal 11(Special Issue): 79-92.

Stuart TE. 1998. Network positions and propensities to collaborate: An investigation of strategic alliance formation in a high-technology industry. Administrative Science Quarterly 43(3): 668-698.

Stuart TE, Hoang H, Hybels RC. 1999. Interorganizational endorsements and the performance of entrepreneurial ventures. Administrative Science Quarterly 44(2): 315-349.

Stuart TE, Sorenson O. 2007. Strategic networks and entrepreneurial ventures. Strategic Entrepreneurship Journal 1(3-4): 211-227.

Thompson P, Chen J. 2011. Disagreements, employee spinoffs and the choice of technology. Review of Economic Dynamics 14(3): 455-474.

Uzzi B. 1996. The sources and consequences of embeddedness for the economic performance of organizations: The network effect. American Sociological Review 61(4): 674-698.

Uzzi B. 1997. Social structure and competition in interfirm networks: The paradox of embeddedness. Administrative Science Quarterly 42(1): 35-68.

Uzzi B, Gillespie JJ. 2002. Knowledge spillover in corporate financing networks: Embeddedness and the firm's debt performance. Strategic Management Journal 23(7): 595-618.

,Wennberg K, Wiklund J, Wright M. 2011. The effectiveness of university knowledge spillovers: Performance differences between university spinoffs and corporate spinoffs. Research Policy 40(8): 1128-1143.

Woo CY, Willard GE, Daellenbach US. 1992. Spin-off performance: A case of overstated expectatations? Strategic Management Journal 13(6): 433-447.

Wooldridge JM. 2003. Introductory Econometrics : A Modern Approach (2nd edn.). South-Western College Pub.: Australia; Cincinnati, Ohio.

Yli-Renko H, Autio E, Sapienza HJ. 2001. Social capital, knowledge acquisition, and knowledge exploitation in young technology-based firms. Strategic Management Journal 22: 587-613.

Zaheer A, Bell GG. 2005. Benefiting from network position: Firm capabilities, structural holes, and performance. Strategic Management Journal 26(9): 809-825.

This article is protected by copyright. All rights reserved. 
Table 1. Descriptive statistics and correlations ${ }^{\mathrm{a}}$

\begin{tabular}{lrrrrrrrrrr}
\hline \multicolumn{1}{c}{ Variable } & Mean & St.Dev. & 1 & 2 & 3 & 4 & 5 & 6 & 7 & 8 \\
\hline 1.Time to breakeven (months) & 18.54 & 21.24 & - & & & & & & & \\
2.Parent hostility & 0.50 & 0.50 & $0.15^{\mathrm{t}}$ & - & & & & & \\
3.Parent hostility (alt. measure) & 0.49 & 0.50 & $0.20^{*}$ & $0.92^{* * *}$ & - & & & & \\
4.Product differentiation & 4.71 & 2.08 & 0.11 & -0.04 & 0.00 & - & & & \\
5.Network development & 0.79 & 0.69 & 0.08 & $0.16^{\mathrm{t}}$ & 0.13 & 0.00 & - & & \\
6.Product quality & 5.52 & 1.20 & -0.11 & -0.01 & -0.07 & $0.15^{\mathrm{t}}$ & 0.03 & - & \\
7.Initial product similarity & 3.92 & 2.38 & $-0.18^{*}$ & 0.06 & 0.03 & $-0.76^{* * *}$ & $-0.15^{\mathrm{t}}-0.10$ & - & - \\
8.R\&D intensity & 15.20 & 18.14 & $0.17^{*}$ & $-0.17^{*}$ & -0.13 & $0.18^{*}$ & -0.12 & $0.22^{* *}$ & $-0.22^{* *}$ & - \\
9.Exploration & 4.97 & 1.59 & $0.15^{\mathrm{t}}$ & 0.02 & -0.01 & $0.16^{\mathrm{t}}$ & 0.10 & $0.32^{* * *}-0.15^{\mathrm{t}}$ & $0.17^{*}$ \\
\hline $\mathrm{N}=144{ }^{\mathrm{t}}<0.10 ;$ & ${ }^{*} \mathrm{p}<0.05 ;{ }^{* *} \mathrm{p}<0.01 ;{ }^{* * *} \mathrm{p}<0.001$ (two-tailed test). Pearson product moment correlations are \\
reported for pairs of continuous variables, Spearman rank correlations are reported for pairs of continuous and \\
dichotomous variables.
\end{tabular}

Table 2. Regression results for time to breakeven ${ }^{\mathrm{a}}$

\begin{tabular}{|c|c|c|c|c|c|c|c|c|c|c|}
\hline & \multicolumn{2}{|c|}{ Model 1} & \multicolumn{2}{|c|}{ Model 2} & \multicolumn{2}{|c|}{ Model 3} & \multicolumn{2}{|c|}{ Model 4} & \multicolumn{2}{|c|}{ Model 5} \\
\hline & $\mathrm{b}$ & s.e. & $\mathrm{b}$ & s.e. & $\mathrm{b}$ & s.e. & $\mathrm{b}$ & s.e. & $\mathrm{b}$ & s.e. \\
\hline \multicolumn{11}{|l|}{ Control variables } \\
\hline Product quality & $-0.201^{* *}$ & 0.074 & $-0.202^{* *}$ & 0.074 & $-0.247^{* *}$ & 0.082 & $-0.200^{* *}$ & 0.068 & $-0.239^{* *}$ & 0.074 \\
\hline Start-up experience & $0.222^{* *}$ & 0.071 & $0.232^{* *}$ & 0.073 & $0.229^{* *}$ & 0.074 & $0.161^{*}$ & 0.072 & $0.158^{*}$ & 0.072 \\
\hline Initial product similarity & $-0.069^{t}$ & 0.038 & $-0.110^{\mathrm{t}}$ & 0.064 & $-0.120^{\mathrm{t}}$ & 0.063 & $-0.129^{*}$ & 0.059 & $-0.136^{*}$ & 0.058 \\
\hline R\&D intensity & 0.005 & 0.005 & 0.008 & 0.006 & 0.008 & 0.006 & $0.015^{*}$ & 0.006 & $0.014^{*}$ & 0.006 \\
\hline Exploration strategy & $0.130^{*}$ & 0.063 & $0.137^{*}$ & 0.058 & $0.139^{*}$ & 0.060 & $0.122^{*}$ & 0.057 & $0.123^{*}$ & 0.059 \\
\hline \multicolumn{11}{|l|}{ Main effects } \\
\hline Parent hostility & & & $0.592^{* *}$ & 0.185 & $0.588^{* *}$ & 0.186 & $0.640^{* * *}$ & 0.181 & $0.632^{* * *}$ & 0.182 \\
\hline Product differentiation & & & -0.064 & 0.067 & 0.009 & 0.077 & -0.084 & 0.062 & -0.012 & 0.075 \\
\hline Network development & & & 0.069 & 0.128 & 0.073 & 0.130 & $-0.283^{\mathrm{t}}$ & 0.153 & $-0.274^{t}$ & 0.157 \\
\hline $\begin{array}{l}\text { Interaction effects } \\
\text { Parent hostility X } \\
\text { product differentiation } \\
\text { Parent hostility X }\end{array}$ & & & & & $0.152^{t}$ & 0.084 & & & $0.148^{t}$ & 0.085 \\
\hline network development & & & & & & & $-0.930^{* * *}$ & 0.255 & $-0.910^{* * *}$ & 0.262 \\
\hline Constant & $2.830^{* * *}$ & 0.093 & $3.084^{* * *}$ & 0.124 & $3.076^{* * *}$ & 0.125 & $3.117^{* * *}$ & 0.123 & $3.107^{* * *}$ & 0.124 \\
\hline $\mathrm{df}$ & 137 & & 134 & & 133 & & 133 & & 132 & \\
\hline $\begin{array}{l}\text { Deviance } \\
\text { (-2 log likelihood) }\end{array}$ & 170.13 & & 170.14 & & 170.08 & & 170.22 & & 170.25 & \\
\hline $\operatorname{LR} X^{2}$ & $14.66^{*}$ & & $21.62^{* *}$ & & $23.65^{* *}$ & & $28.94^{* * *}$ & & $30.95^{* * *}$ & \\
\hline
\end{tabular}

$\mathrm{N}=144$; unstandardized coefficients. ${ }^{\mathrm{t}}<0.10 ;{ }^{*} \mathrm{p}<0.05 ;{ }^{* *} \mathrm{p}<0.01 ;{ }^{* * *} \mathrm{p}<0.001$ (two-tailed test).

This article is protected by copyright. All rights reserved. 